\title{
Review of Russell Hardin's How do you know?: the economics of ordinary knowledge. Princeton: Princeton University Press, 2009, 256 pp.
}

\author{
FRANK HINDRIKS \\ University of Groningen
}

Although some people are curious and enjoy learning things about the world even if they are of only remote interest to their daily lives, most people are not very inquisitive and set out to gather information only on a need-to-know basis. In his latest book Russell Hardin argues that people are perfectly rational when they refrain from embarking on a quest for knowledge. Ignorance turns out to be bliss, not because possessing knowledge would be disturbing, but because we maximize our utility by not investing much in knowledge acquisition.

The core of what Hardin calls his 'economic theory of ordinary knowledge' consists of the thought that costs and benefits influence what we come to know. His main thesis is that cost-benefit analysis explains why most non-scientists know very little about anything. Hardin puts this thesis to a somewhat unexpected use-to defend the idea that human beings are rational agents. The charge is that we often do stupid things and that this goes to show that we are not very rational. Hardin's response is that the stupidity is only apparent. Allegedly stupid actions may be due to our ignorance and ignorance is usually rational since for practical purposes it is often not worth the trouble to learn more (i.e., the returns on investment in knowledge are frequently negative). In light of the rationality of our ignorance, it would be foolish to insist that the actions really are irrational. Hardin applies these ideas to several domains including medicine, culture, and religion, which I only mention here, and morality and politics, on which I shall elaborate.

In relation to politics Hardin uses his thesis of the rationality of ignorance-as I will call it-to explain why so many people defy the logic of collective action. His main example is voting. The chance that your vote will make a difference is very small. Even when the cost of voting is small, the negligible chance of making a difference makes voting irrational for most, if not all of us. In spite of this, many people do vote. 
Does this mean that they are indeed irrational? Not necessarily. They might fail to understand the logic of collective action. And the expected benefits to understanding it are so low that it is rational for them not to invest in trying to understand it. The rationality of their ignorance in turn reflects on the rationality of their voting behavior. It would be irrational for them to vote, if they understood the logic of collective action. Given that they do not understand it, however, voting may be rational for them. The reason for this is that the rationality of an action has to be evaluated relative to the beliefs the agent has. After all, according to rational choice theory, people maximize their expected utility. One might object that voting is irrational for them after all, because it is due to ignorance or to beliefs that are mistaken or unjustified. In response, it is worth pointing out that it is far from obvious that the irrationality of a belief affects the rationality of an action within the context of rational choice theory. To the extent that it does, the objection is, once again, answered by his thesis of the rationality of ignorance.

What should we make of this rather ingenious line of reasoning? Hardin does not present any systematic evidence in favor of his explanation. The evidence he presents is anecdotal. On numerous occasions he has experienced difficulty in explaining the logic of collective action. From this he infers that it is indeed very difficult to understand. Although he admits it is not quite as difficult as quantum mechanics, he surmises that for most people it is not comprehensible at all. Hardin explains this in turn by claiming that since the costs of voting tend to be small, most people have little incentive to try to understand the logic of collective action (p. 73).

The main problem I see with this argument is that the core idea is in fact very easy to grasp. The only thing people need to know in order to realize that voting does not result in any direct benefit is that the chance that their vote will make a difference to the outcome is small. Most people are well aware of this (even if they overestimate it). In light of this it is implausible that, as Hardin implies, many people who vote do so because their cost-benefit calculations turn out positively. Note also that an alternative interpretation of Hardin's conversations is readily available. His interlocutors simply do not believe that the logic of collective action should be the decisive factor insofar as voting is concerned. They assign, and they believe other people assign, more 
significance to reasons for voting that Hardin is inclined to dismiss as irrelevant.

Hardin admits that some people might vote because they regard not voting as inappropriate, perhaps even immoral, and that such people might justify their attitudes and actions by rhetorically asking 'What if everyone did that?' - a question that appears to lie at the heart of what might be called 'the logic of moral action'. However, he plays down the importance of this explanation by suggesting that people often experience feelings of guilt and regret for not voting when their party loses and that such feelings should be independent of the fate of their party if the issue were really a moral one for them (p. 73). He takes this to imply that the feelings are non-moral and that they are based on the (fallacious) idea that individuals can reasonably expect to influence elections after all.

Matters might be slightly more complex. Perhaps the people Hardin describes rationalized their not-voting by thinking to themselves that their vote would not make a difference anyway. This rationalization would presumably survive if their party were to win since there would not really be an occasion for guilt or regret in the first place. The rationalization may break down, however, if their party loses. They might then realize that they-just as many others-succumbed to a line of reasoning to which they should not give in. Their feelings of guilt and regret might have a social aspect in that they feel bad about falling foul of a line of reasoning that is damaging if too many people give in to it. From a moral perspective the logic of collective action might in fact put extra pressure on individuals to vote: people might regard the very fact that not voting is tempting for all as a consideration that ultimately counts in favor of them voting. This somewhat more complex line of reasoning, which revolves around the tension between the logic of collective action and the logic of moral action, suggests the feelings Hardin discusses might well be sensible even on a moral interpretation.

The basic idea underlying this interpretation is that moral considerations and cost-benefit analysis may pull in different directions. Hardin devotes a chapter to moral knowledge in which he refers to this as "the dualism of practical reason" (which he traces back to Henry Sidgwick). He seems to have a somewhat ambivalent attitude towards this idea. He criticizes the thought that moral norms serve our collective benefit by providing an example of a destructive social practice-the inhabitants of St. Kilda followed a norm that required them to spread a 
mixture of fulmar oil and dung on the wound where the umbilical cord was cut loose, which decimated the island's population (p. 115). In addition to this he maintains that children are provided with both moral and prudential reasons against lying and breaking promises: such actions are wrong, but also harm our long-term self-interest, because they make us untrustworthy. Hardin goes as far as claiming that acting morally typically coincides with acting from self-interest (p. 111). A few pages later, however, he argues that people have little incentive to acquire moral knowledge, because we rarely need it and because acting on such knowledge is often costly. My problem with this chapter is not so much that I disagree with particular claims, but that I am somewhat lost as to what the overall point is supposed to be.

A question that remains is why Hardin talks about moral knowledge rather than moral beliefs. The idea that there is such a thing as moral knowledge is rather controversial as it appears to presuppose that there are objective moral truths. But perhaps it is due to Hardin's skepticism about the idea that ordinary people make a sharp distinction between knowledge and belief in general. Hardin is rather dismissive of the philosophical literature on knowledge and its relation to belief, which he regards as "arcane" (p. 101). He also maintains that the distinction between belief and knowledge is practically useless. It is not obvious, however, that this is true. Suppose I have misplaced my keys, but I know they are somewhere in my house (I even know that I know this). Surely my search behavior will be different as compared to the situation in which I merely believe they are somewhere in my house. Only in the latter case would I consider retracing the steps I made outside of the house earlier today.

Hardin seems to believe recourse is needed to some 'super knower' if the traditional philosophical distinction between knowledge and belief is to be maintained. It is, however, not clear why. The idea that what you know is true, whereas what you merely believe need not be, is deeply ingrained in the common sense conception of knowledge (the question Hardin has used as the title of his book is often used to express skepticism about the epistemic status of a claim someone has just made, and in those cases presupposes the very distinction Hardin is skeptical of). The distinction may well be a genuine one even if in particular cases we have no means to establish with certainty whether someone knows something or merely believes it, and even if there is no 'super knower' who knows this. So Hardin's skepticism concerning the 
distinction seems unjustified (which may not bother him, because he is not convinced that justification is a useful notion). Hardin's dismissal of the philosophical literature is in fact somewhat annoying. He claims that the whole distinction between knowledge and belief is unimportant for his purposes (p. 26). In light of this, it would make more sense to sidestep the issue altogether.

I also find Hardin's dismissal of psychological research about constraints on decision-making too glib. Here is his characterization of it: "[I]ts arguments and conclusions range from the often dazzling and powerful to the ordinary and merely commonsensical. That literature is full of ad hoc labels for countless patterned behaviors" (p. xii). What Hardin presents us with is a series of somewhat speculative and loosely connected arguments and observations based on armchair cost-benefit analysis. Ideally science provides theoretical understanding of phenomena that is supported by empirical evidence. Hardin may be right when he suggests that psychology often gets stuck in piecemeal empiricism. However, armchair rationalism does not provide for a very satisfactory alternative.

Frank Hindriks is assistant professor at the faculty of philosophy, University of Groningen (the Netherlands). His research interests include ethics, political philosophy, and economic methodology. Some of his recent publications are "Constitutive rules, language, and ontology" Erkenntnis (2009), "Corporate responsibility and judgment aggregation" Economics and Philosophy (2009), and "Intentional action and the praiseblame asymmetry" Philosophical Quarterly (2008).

Contact e-mail: <f.a.hindriks@rug.nl>

Website: <http://www.rug.nl/staff/f.a.hindriks/index> 